Original

\title{
Clinical evaluation of guided tissue regeneration combined with autogenous bone or autogenous bone mixed with bioactive glass in intrabony defects
}

\author{
Vikender S. Yadav1), Satish C. Narula1), Rajinder K. Sharma1), \\ Shikha Tewari1) and Renu Yadav2) \\ 1)Department of Periodontics and Oral Implantology, Government Dental College, Rohtak, Haryana, India \\ 2)Private Practice, Gurgaon, Haryana, India
}

(Received 20 June and accepted 5 October 2011)

\begin{abstract}
Conflicting data exist on the combined use of grafting materials and barrier membranes in comparison to guided tissue regeneration (GTR) with membrane alone. The aim of the present study was to compare the clinical outcomes of GTR with collagen membrane (CM) alone (control group) or $\mathrm{CM}$ combined with autogenous bone graft (test group 1) or autogenous bone mixed with bioactive glass (test group 2) in intrabony defects. A total of 32 intraosseous defects in 22 subjects were treated randomly. After 6 months, significant probing depth reduction, clinical attachment level gain (CAL) and defect resolution were observed in all groups with significantly greater improvements in the test groups. There was no significant difference between the two test groups in any parameter. Results of the present study suggest that autogenous bone can be mixed with bioactive glass if the amount of the harvested bone is not sufficient. (J Oral Sci 53, 481-488, 2011)
\end{abstract}

Keywords: periodontal regeneration; collagen membrane; autogenous bone graft; bioactive glass; intrabony defects.

Correspondence to Dr. Vikender S. Yadav, Department of Periodontics and Oral Implantology, Government Dental College, Rohtak 124001, Harayana, India

Tel: +91-8901536093

Fax: +91-1262-213876

E-mail: vikenderyadav@gmail.com

\section{Introduction}

Periodontal therapy is aimed at arresting the progression of disease by controlling the infection, and regenerating the lost attachment apparatus of the tooth. The use of bone grafts and guided tissue regeneration (GTR) are among the techniques widely used to reach this therapeutic endpoint.

Numerous studies have reported successful clinical results when employing collagen membranes for GTR therapy (1). The rationale for selecting collagen as a barrier membrane was based on the fact that type-1 collagen is the main constituent of periodontal connective tissue. In addition, collagen materials also exhibit chemotactic function for fibroblasts, hemostatic property, weak immunogenicity and osteoblast adhesion activity (1). However, it is critical in GTR that the space underneath the barrier is maintained for an adequate period of time during healing for complete periodontal regeneration to occur. In cases where the membrane collapsed into the defects or towards the roots, reduced amounts of bone were formed due to limited space available for periodontal ligament cells to repopulate $(2,3)$. In order to compensate for the lack of space-maintaining effect of membranes available and/or to promote bone formation, various bone grafting materials were used as adjuncts to the GTR technique. However, the results obtained to date from controlled human studies investigating the benefit of combined use of a GTR barrier with grafting materials are contradictory (4-16) and many of these studies used demineralized freeze dried bone allograft (DFDBA) as 
grafting material $(4-7,9,10,14-16)$. Therefore, it is not completely clear whether combination therapy (GTR plus bone grafting) is more effective than GTR alone. Moreover, perusal of the available literature revealed no study comparing the treatment outcomes of GTR with and without autogenous bone.

Although autogenous grafts are still considered to be the gold standard as they are the most predictable material (17), only a limited amount of autogenous bone can be procured from intraoral sites which may not be sufficient for complete fill of defects. Meanwhile, alloplastic materials, particularly bioactive glass, may represent a possible alternative to be mixed with autogenous bone for the treatment of intrabony defects. Since bioactive glass is reported to promote adsorption and the concentration of proteins utilized by osteoblasts to form mineralized extracellular matrix, it thus promotes osteogenesis by allowing rapid formation of new bone (18). Some histological studies have shown that the use of bioactive glass induces a significant increase in newly formed cementum and attachment and that apical downgrowth of the junctional epithelium can be prevented (19-21). Results from clinical and histological studies also indicated that bioactive glass is easy to handle, biocompatible, has haemostatic properties, and osteoconductive as well as potentially osteoinductive effects (22-24).

The aim of this prospective randomized controlled clinical trial was therefore to evaluate the clinical outcomes of collagen membrane alone and in combination with autogenous graft or autogenous graft mixed with bioactive glass when used in periodontal intrabony defects.

\section{Materials and Methods}

\section{Study population and experimental design}

Thirty-two periodontal intrabony defects in 22 subjects (12 males and 10 females; age range: 20 to 49 years; mean age: $33.2 \pm 7.4$ years) diagnosed to have moderate to severe chronic periodontitis were selected among the patients attending the Department of Periodontics and Oral Implantology, Government Dental College, Pt. B. D. Sharma University of Health Sciences, Rohtak, Haryana, India. All clinical procedures were performed in accordance with the Declaration of Helsinki and the Good Clinical Practice Guidelines. Each patient provided signed informed consent to participate in the study. The informed consent and research protocols were approved by the Institutional Review Board.

Medical and dental histories were reviewed for the following exclusion criteria: (1) systemic disease that might influence the outcome of the therapy (2) smokers
(3) pregnant or lactating patients (4) use of antibiotics or any drug therapy known to interfere with wound healing during the previous 6 months.

The patients were consecutively enrolled in the study when the following inclusion criteria were fulfilled: 1) presence of at least one radiographically detectable intrabony defect with a residual probing depth of $\geq 6 \mathrm{~mm} 2$ months after completion of scaling and root planing, 2) either 2- or 3-wall or combined 2- and 3-wall intrabony defect with a depth of $\geq 3 \mathrm{~mm}$ whose architecture had to be confirmed by direct observation during surgical exposure, and 3) a good level of oral hygiene [plaque index $(\mathrm{PI})<1](25)$.

Eleven defects ( 3 patients with two defects each and 5 patients with one defect each) in the control group received a bioresorbable type 1 bovine collagen barrier (Healiguide, Advanced Biotech Products (P) Ltd., Encoll Corp., Fremont, CA, USA). Ten defects (3 patients with two defects each and 4 patients with one defect each) in test group $1\left(\mathrm{TG}_{1}\right)$ were treated with autogenous bone graft covered with collagen membrane while the 11 defects (4 patients with two defects each and 3 patients with one defect each) in test group $2\left(\mathrm{TG}_{2}\right)$ were treated with a membrane supported by autogenous graft mixed with bioactive glass (PerioGlas, US Biomaterials, Alachua, FL, USA).

\section{Clinical Measurements}

Clinical parameters including plaque index (PI), gingival index (GI) (26), pocket probing depth (PPD) and clinical attachment level (CAL) were assessed immediately before surgery (baseline) and 6 months after the surgical procedure. For CAL, the cementoenamel junction (CEJ) was used as the reference point. The deepest point in each defect was identified and this was used as the site for measurements. All measurements were recorded using a University of North Carolina probe (UNC-15, Hu-Friedy Mfg. Inc, Chicago, IL, USA) and rounded up to the nearest millimetre. Intra-examiner reproducibility was assessed with a calibration exercise performed at two separate occasions, 48 hours apart. Calibration was accepted if $>90 \%$ of the recording could be reproduced within a difference of $1.0 \mathrm{~mm}$.

\section{Surgical procedure}

Following the administration of local anaesthesia, intrasulcular incisions were made and buccal and lingual full thickness mucoperiosteal flaps were raised. Alveolar bone was exposed $\geq 3 \mathrm{~mm}$ beyond the defect margin, and a periosteal releasing incision was performed if deemed necessary to assure complete membrane coverage 

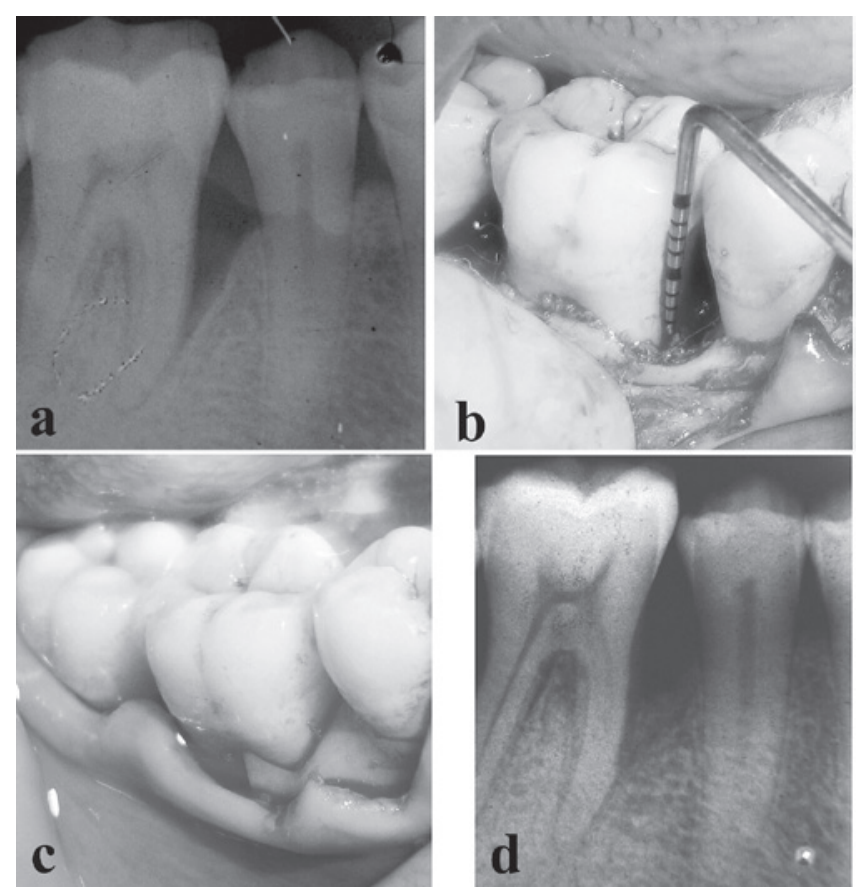

c

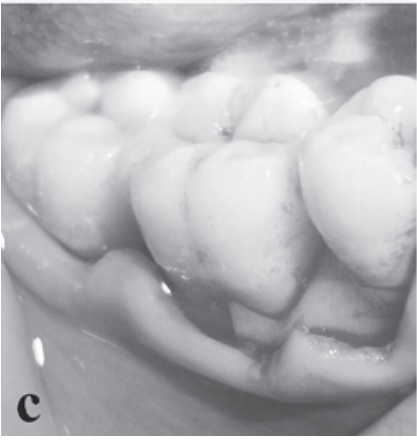

Fig. 1 Representative case from the control group: a) Preoperative radiograph, b) Intrabony defect after debridement, c) Collagen membrane adapted coronal to crest of defect, d) Postoperative radiograph.

without tension at the time of suturing. Granulation tissue was removed from the intraosseous defects, and the roots were scaled and planed thoroughly with Gracey curets (Hu-Friedy) and ultrasonic instruments to remove residual mineralized deposits, but not necessarily the root cementum. Afterwards, the defects were evaluated and, if they met the inclusion criteria with regard to defect configuration, they were randomly assigned to one of the treatment groups. In the control group, collagen membrane was trimmed according to the template prepared for each defect. The membrane was then positioned onto the defect area, and adapted immediately coronal to the interproximal bone crest, extending 2-3 $\mathrm{mm}$ apically and laterally over the adjacent bone (Fig. 1). The adhesion of membrane to bone and root surface precluded the need for suturing the membrane.

Depending on the size of the intrabony defect, a corticocancellous block of autogenous bone was harvested from the mandibular retromolar area using a trephine bur of $4 \mathrm{~mm}$ in diameter with markings up to $10 \mathrm{~mm}$ at $2.0-\mathrm{mm}$ increments. Harvested bone was crushed into smaller pieces prior to filling the defects (Fig. 2). For test group 2, autogenous graft and bioactive glass (1:1 ratio) were mixed with saline in a sterile dappen dish until the graft material was clinically manageable (Fig. 3). In test sites, before suturing, the membrane was slightly raised

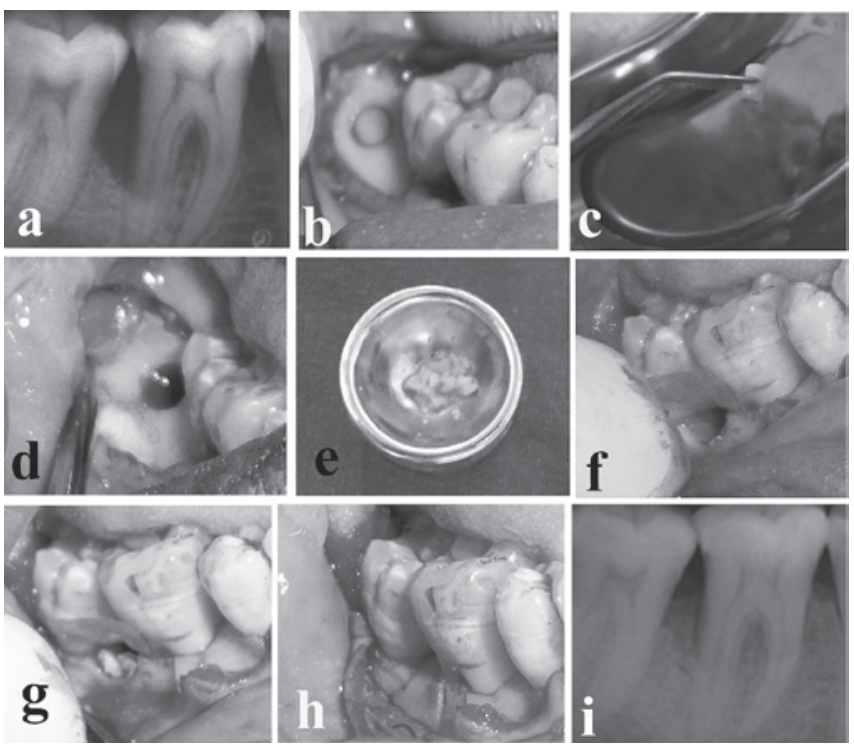

Fig. 2 Representative case from the test group 1: a) Preoperative radiograph, b) Mandibular retromolar area exposed and osteotomy done with trephine bur, c) Corticocancellous block of harvested bone, d) Osteotomy site after removal of autogenous bone block, e) Harvested bone crushed into smaller pieces to fill the defect, f) Positioning of membrane over the defect, g) Autogenous graft placed beneath the membrane to fill the defect, h) Collagen membrane adapted coronal to crest of defect, i) Postoperative radiograph.

on one side and small increments of graft material were added, starting from the bottom and adapted well to its configuration. Subsequently, the membrane was adapted over the defect filled with graft material.

Mucoperiosteal flaps were positioned at the presurgical level or slightly coronal to achieve primary closure of the interdental area without any tension and closed with vertical or horizontal mattress sutures (Sterisil 4-0 silk, Stericat Gutstrings).

\section{Postoperative Care}

Oral antibiotics (amoxicillin $500 \mathrm{mg}$ ) and analgesics (ibuprofen 400mg) every 8 hours were prescribed for 7 days. Patients were instructed to rinse twice daily with $0.2 \%$ chlorhexidine gluconate mouth rinse for 4 weeks postoperatively and not to brush the treated area during the first 2 weeks. No interdental cleaning was allowed in the first 4 weeks after the procedure. If the membrane became exposed during the healing phase, patients were prescribed 1\% chlorhexidine gel (Hexigel, ICPA Health Products, Mumbai, India) to be applied two times per day with a cotton pellet onto the exposed material. Sutures were removed 10 days after the surgery. 

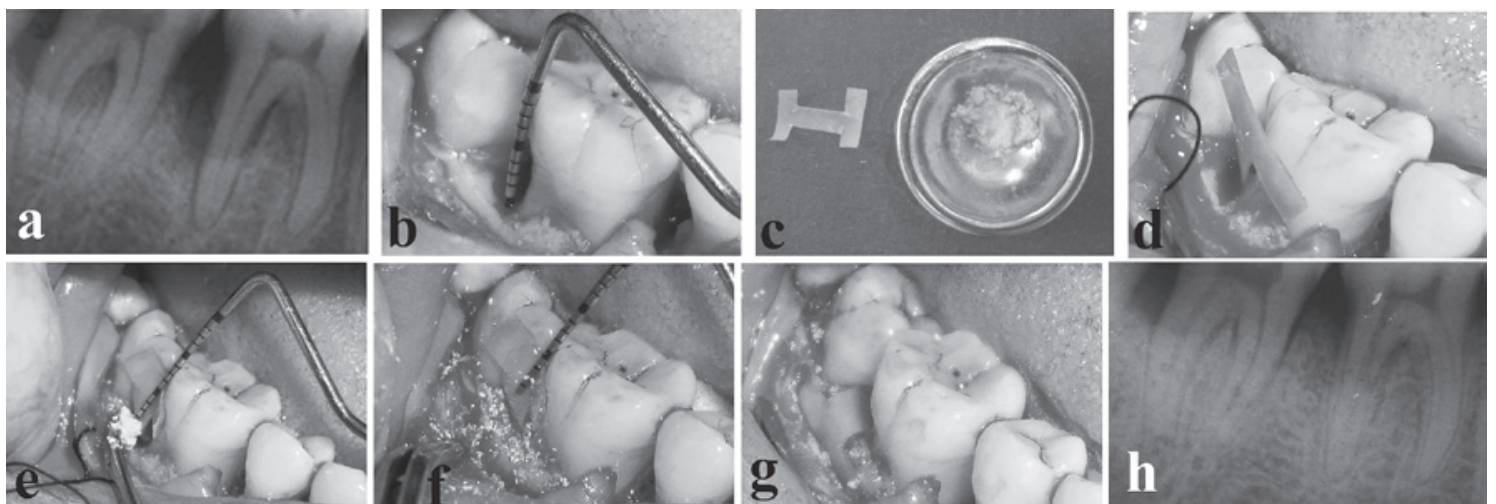

Fig. 3 Representative case from the test group 2: a) Preoperative radiograph, b) Intrabony defect after debridement, c) Trimmed collagen membrane and composite graft (autogenous bone plus bioactive glass), d) Positioning of membrane over the defect, e) Composite graft carried to place in the defect, f) Composite graft placed beneath the membrane to fill the defect, g) Collagen membrane adapted coronal to crest of defect, h) Postoperative radiograph.

Table 1 Baseline characteristics of patients and defects

\begin{tabular}{lcccc}
\hline Variable & Control group (CG) & $\mathrm{TG}_{1}$ & $\mathrm{TG}_{2}$ & $P$ value \\
\hline PI & $0.57 \pm 0.33$ & $0.55 \pm 0.33$ & $0.62 \pm 0.24$ & 0.889 \\
GI & $0.82 \pm 0.24$ & $0.75 \pm 0.29$ & $0.80 \pm 0.45$ & 0.821 \\
PPD (mm) & $8.90 \pm 1.97$ & $9.30 \pm 2.45$ & $9.40 \pm 2.87$ & 0.971 \\
CAL (mm) & $8.70 \pm 2.54$ & $8.90 \pm 2.99$ & $9.10 \pm 3.84$ & 0.981 \\
Age (years) & $31.6 \pm 7.3$ & $34.1 \pm 8.09$ & $34.1 \pm 7.75$ & 0.621 \\
Radiographic bone level (mm) & $9.81 \pm 2.57$ & $9.96 \pm 3.05$ & $10.20 \pm 3.96$ & 0.951 \\
Crestal bone level (mm) & $3.59 \pm 1.38$ & $3.29 \pm 1.22$ & $3.56 \pm 1.49$ & 0.893 \\
Depth of defect (mm) & $6.22 \pm 1.28$ & $6.67 \pm 1.90$ & $6.64 \pm 2.59$ & 0.839 \\
Male/Female & $4 / 4$ & $4 / 3$ & $4 / 3$ & \\
Defects & 11 & 10 & 11 & \\
Maxillary/Mandibular & $5 / 6$ & $3 / 7$ & $4 / 7$ & \\
Anterior/Posterior & $2 / 9$ & $3 / 7$ & $3 / 8$ & \\
2-wall & 5 & 3 & 1 & 2 \\
3-wall & 2 & 6 & 5 & \\
2-or 3-wall & 4 & & & \\
\hline
\end{tabular}

\section{Radiographic evaluation}

With the aid of an individual tray, standardized radiographs were taken at baseline and 6 months postoperatively for each defect. Interpretation of digitalized radiographs was carried out by means of analytical Image $J \circledR$ software $(1.34 \mathrm{~s}$; US National Institutes of Health, Bethesda, MD, USA) for the following parameters: (a) the distance from CEJ to the bottom of the intrabony defect (BD), representing the radiographic bone level (RBL), (b) the distance from CEJ to the bone crest (CBL), and (c) the distance from bone crest to $\mathrm{BD}$, representing the intrabony component (IC) of the defect. The differences were calculated as height of bone fill and crestal bone resorption. The percentage defect resolution was calculated by the formula:

$$
\frac{\left(\mathrm{IC}_{\text {baseline }}\right)-\left(\mathrm{IC}_{6 \text { months }}\right)}{\left(\mathrm{IC}_{\text {baseline }}\right)} \times 100
$$

\section{Statistical analysis}

Each defect was considered as a statistical unit. Descriptive data that included Mean \pm Standard Deviation (SD) were calculated for each parameter at baseline and 6 months. Pre and postoperative changes in these parameters were evaluated by Wilcoxon signed-ranks test and differences between groups by Mann Whitney$U$ test. Kruskal Wallis test was applied to compare the parameters in three groups at baseline. The level of significance was set at the probability value $(P) \leq 0.05$. 
Table 2 Clinical parameters at baseline and at 6-month evaluation

\begin{tabular}{|c|c|c|c|c|c|}
\hline \multirow[b]{2}{*}{ Parameter } & \multirow[b]{2}{*}{ group } & \multicolumn{4}{|c|}{ Time point } \\
\hline & & Baseline & 6 months & difference & $P$ value* \\
\hline \multirow[t]{6}{*}{ PPD } & $\mathrm{CG}$ & $8.90 \pm 1.97$ & $6.10 \pm 1.66$ & $2.80 \pm 0.79$ & $0.004^{* * *}$ \\
\hline & $\mathrm{TG}_{1}$ & $9.30 \pm 2.45$ & $4.70 \pm 1.64$ & $4.60 \pm 1.35$ & $0.005^{* * *}$ \\
\hline & $\mathrm{TG}_{2}$ & $9.40 \pm 2.87$ & $5.40 \pm 2.32$ & $4.00 \pm 1.25$ & $0.005^{* * *}$ \\
\hline & $P$ value $^{* *}\left(\mathrm{CG}\right.$ versus $\left.\mathrm{TG}_{1}\right)$ & 0.818 & 0.083 & $0.003^{* * *}$ & - \\
\hline & $P$ value $^{* *}\left(\mathrm{CG}\right.$ versus $\left.\mathrm{TG}_{2}\right)$ & 0.849 & 0.398 & $0.017^{* * *}$ & - \\
\hline & $P$ value ${ }^{* *}\left(\mathrm{TG}_{1}\right.$ versus $\left.\mathrm{TG}_{2}\right)$ & 0.849 & 0.398 & 0.267 & - \\
\hline \multirow[t]{6}{*}{ CAL } & $\mathrm{CG}$ & $8.70 \pm 2.54$ & $6.60 \pm 2.22$ & $2.10 \pm 0.74$ & $0.004^{* * *}$ \\
\hline & $\mathrm{TG}_{1}$ & $8.90 \pm 2.99$ & $4.70 \pm 2.26$ & $4.20 \pm 1.69$ & $0.005^{* * *}$ \\
\hline & $\mathrm{TG}_{2}$ & $9.10 \pm 3.84$ & $5.70 \pm 3.62$ & $3.40 \pm 0.70$ & $0.004^{* * *}$ \\
\hline & $P$ value $^{* *}\left(\mathrm{CG}\right.$ versus $\left.\mathrm{TG}_{1}\right)$ & 0.909 & 0.057 & $0.005^{* * *}$ & \\
\hline & $P$ value ${ }^{* *}\left(\mathrm{CG}\right.$ versus $\left.\mathrm{TG}_{2}\right)$ & 0.879 & 0.619 & $0.002^{* * *}$ & \\
\hline & $P$ value ${ }^{* * *}\left(\mathrm{TG}_{1}\right.$ versus $\left.\mathrm{TG}_{2}\right)$ & 0.879 & 0.513 & 0.259 & \\
\hline
\end{tabular}

*Wilcoxon signed rank test, $* *$ Mann Whitney $U$-test, ***statistically significant

Table 3 Radiographic parameters at baseline and at 6-month evaluation

\begin{tabular}{lccc}
\hline Parameters & Control group & Test group 1 & Test group 2 \\
\hline $\mathrm{RBL}_{\text {baseline }}$ & $9.81 \pm 2.57$ & $9.96 \pm 3.05$ & $10.20 \pm 3.96$ \\
$\mathrm{RBL}_{6 \text { months }}$ & $8.65 \pm 2.24$ & $6.26 \pm 2.31$ & $7.31 \pm 3.83$ \\
$\mathrm{RBL}_{\text {gain }}$ & $1.16 \pm 0.82$ & $3.70 \pm 1.55$ & $2.89 \pm 0.69$ \\
$\mathrm{CBL}_{\text {baseline }}$ & $3.59 \pm 1.38$ & $3.29 \pm 1.22$ & $3.56 \pm 1.49$ \\
$\mathrm{CBL}_{6 \text { months }}$ & $4.09 \pm 1.43$ & $3.41 \pm 1.25$ & $3.76 \pm 1.54$ \\
$\mathrm{CBL}_{\text {resorption }}$ & $0.50 \pm 0.014^{*}$ & $0.12 \pm 0.11^{*}$ & $0.20 \pm 0.16^{*}$ \\
$\mathrm{IC}_{\text {baseline }}$ & $6.22 \pm 1.28$ & $6.67 \pm 1.90$ & $6.64 \pm 2.59$ \\
$\mathrm{IC}_{6 \text { months }}$ & $4.56 \pm 1.24$ & $2.85 \pm 1.39$ & $3.55 \pm 2.54$ \\
$\mathrm{IC}_{\text {reduction }}$ & $1.66 \pm 0.89$ & $3.82 \pm 1.57$ & $3.09 \pm 0.66$ \\
$($ Defect resolution $)$ & $(26.7 \%)^{*}$ & $(57.3 \%)^{*}$ & $(46.5 \%)^{*}$ \\
\hline *statistically significant $(P<0.05)$ & &
\end{tabular}

\section{Results}

Two patients with one defect each (one in control group and one in $\mathrm{TG}_{2}$ ) discontinued the study during the follow up period due to circumstances unrelated to the study protocol; thus a total number of 30 defects (10 in each group) were evaluated to assess the outcome of the study.

There were no relevant differences in age and gender distribution between the groups. The distribution and configuration of the defects in the three groups were similar. There were no significant differences in the mean values of clinical and radiographic parameters observed at baseline (Table 1).

Complete gingival wound closure for primary intention healing was accomplished for all defect sites. Nevertheless, membrane exposure was a common event in all the groups. A total of $53.3 \%$ of all the membranes (seven in the control group, four in $\mathrm{TG}_{1}$ and five in $\mathrm{TG}_{2}$ ) became exposed to the oral environment 2 and 3 weeks after surgery, but no signs of excessive inflammation were seen. There was no significant difference in the frequencies of membrane exposure between the groups (Pearson, chi-square test).

Patients in all treatment groups exhibited consistent and comparable oral hygiene standards. A statistically significant improvement was observed in the three groups in terms of PPD, CAL and radiographic parameters $(P$ $<0.05$, Tables 2 and 3). The differences in the mean values of PPD reduction, CAL gain, amount of bone fill and crestal bone resorption between the control and test groups were statistically significant, but there was no significant difference between the two test groups.

Reviewing the distribution of sites, PPD reduction of $\geq 4 \mathrm{~mm}$ was recorded in $20 \%$ of the control defects, $80 \%$ of $\mathrm{TG}_{1}$ and $60 \%$ of $\mathrm{TG}_{2}$. CAL gains of $\geq 4 \mathrm{~mm}$ were obtained in $60 \%$ of $\mathrm{TG}_{1}$ defects, $50 \%$ of $\mathrm{TG}_{2}$ and none of the control defects. A defect resolution of $26.7 \%$ was obtained in the control group, while the corresponding 
value was $57.3 \%$ in $\mathrm{TG}_{1}$ and $46.5 \%$ in $\mathrm{TG}_{2}$.

\section{Discussion}

The objective of the present study was to evaluate and compare the clinical outcomes of GTR therapy with and without bone graft materials in intrabony defects. To limit the patient- and defect-based confounding factors, the study was carried out in non-smoking, compliant subjects with comparable defect and subject characteristics.

Healing was uneventful in all the cases. Moreover, membrane exposure was a common event in all groups and $53.3 \%$ of all membranes became exposed to the oral environment. However, it seems that, if proper pre- and postoperative anti-infective care is provided, membrane infection can be controlled and good regenerative results obtained (27).

There was a mean CAL gain of $2.1 \mathrm{~mm}$ in the control group, $4.2 \mathrm{~mm}$ in $\mathrm{TG}_{1}$ and $3.4 \mathrm{~mm}$ in $\mathrm{TG}_{2}$ compared with the baseline. This finding is in agreement with the conclusions of a recent systematic review (28), which showed that intrabony defects treated with collagen barrier without grafting materials resulted in a mean CAL gain of $2.44 \mathrm{~mm}$, with a range of $2.0 \mathrm{~mm}$ to $2.58 \mathrm{~mm}$ and collagen barriers with graft material resulted in a mean CAL gain of $3.48 \mathrm{~mm}$, with a range of $2.3 \mathrm{~mm}$ to 4.1 $\mathrm{mm}$. Our results are also in good conformity with those of other authors who reported enhanced clinical success when GTR was performed with barrier membranes and bone replacement grafts (4-8). These findings support the hypothesis that the presence of physical support under the membrane helps to maintain its position when the flaps are sutured over the defect, exerting pressure on the membrane itself. Furthermore, the bone grafts may also contribute to wound stability, which is a crucial factor for obtaining periodontal regeneration (29). This may also be the reason why a lesser gain in clinical attachment was observed in the control group relative to test groups.

On the contrary, other researchers have reported that the clinical improvements observed with the combined use of GTR and bone grafts were not significantly different from those obtained with GTR alone (9-14). Some researchers have even reported a reduced amount of tissue regeneration with the combined technique $(15,16)$. These authors hypothesized that the biomaterial under the membrane may, in fact, hinder coronal migration and proliferation of progenitor cells from the periodontal ligament into the defect site.

There were no statistically significant differences in any of the investigated clinical parameters between $\mathrm{TG}_{1}$ and $\mathrm{TG}_{2}$. These results are, however, in contrast to the study reported by Zafiropoulos et al. (30), which demon- strated that the use of a composite autogenous- alloplast graft with a bioabsorbable membrane led to significantly greater gain of clinical attachment and hard tissue formation compared to that observed with autogenous bone grafts alone with membrane. However, it should also be noted that the study was non-randomized, included smokers and the preoperative probing depths were not taken into consideration. Rather, it is important to note that the results of the present study prove the superior outcomes (difference of $0.6 \pm 1.9 \mathrm{~mm}$ for PPD reduction and of $0.8 \pm 1.9 \mathrm{~mm}$ for CAL gain) with autogenous graft (pure) as compared to autogenous graft mixed with bioactive glass, though the difference was not significant.

A significantly greater amount of bone fill and lesser crestal resorption were observed in test groups as compared to the control group. These findings are in agreement with those of Paolantonio et al. (8) and Gouldin et al. (10). In contrast, Batista et al. (13) and Trejo et al. (14) showed more positive results with membrane treatment alone. It may be speculated that the type of membranes and bone grafts used, study design and defect factors might have influenced the results.

Autogenous grafts are osseoinductive and result in the formation of new bone faster than alloplastic materials which are exclusively osseoconductive (31). It was suggested that a mixture of autogenous bone and these materials should be used to overcome the lack of osseoinductivity of alloplastic materials (32). Bioactive glass has also been successfully used as a composite graft with autogenous bone in sinus lift procedures $(33,34)$. Limited clinical data exist on the use of composite grafts in the treatment of periodontal intrabony defects $(30,32)$. In the present study, the clinical attachment gain observed with the two test groups was not significantly different, suggesting that autogenous bone can be mixed with bioactive glass if the amount of the harvested bone is not sufficient.

Clinical findings of this study were not validated by re-entry and/or by histologic analysis. Therefore, inferences regarding the nature of healing contributing towards the gain in clinical attachment level could not be made. However, to the best of our knowledge, this is the first study to compare clinical outcomes of GTR with and without autogenous bone or autogenous bone combined with bioactive glass in periodontal intrabony defects. Further studies with a larger sample size and long-term observations would verify the findings presented here.

\section{Acknowledgments}

The authors would like to thank Dr. Sanjay Tewari, Principal, Government Dental College, Rohtak, for 
providing all the facilities for successful completion of this study.

\section{References}

1. Bunyaratavej P, Wang HL (2001) Collagen membranes: a review. J Periodontol 72, 215-229.

2. Caton J, Wagener C, Polson A, Nyman S, Frantz B, Bouwsma O, Blieden T (1992) Guided tissue regeneration in interproximal defects in the monkey. Int J Periodontics Restorative Dent 12, 266-277.

3. Sallum EA, Sallum AW, Nociti FH, Marcantonio RA, de Toledo S (1998) New attachment achieved by guided tissue regeneration using a bioresorbable polylactic acid membrane in dogs. Int J Periodontics Restorative Dent 18, 502-510.

4. Schallhorn RG, McClain PK (1988) Combined osseous composite grafting, root conditioning, and guided tissue regeneration. Int J Periodontics Restorative Dent 8, 8-31.

5. Bowers GM, Chadroff B, Carnevale R, Mellonig J, Corio R, Emerson J, Stevens M, Romberg E. (1989) Histologic evaluation of new attachment apparatus formation in humans. Part II. J Periodontol 60, 675-682.

6. Blumenthal N, Steinberg J (1990) The use of collagen membrane barriers in conjunction with combined demineralized bone-collagen gel implants in human infrabony defects. J Periodontol 61, 319-327.

7. McClain PK, Schallhorn RG (1993) Long-term assessment of combined osseous composite grafting, root conditioning, and guided tissue regeneration. Int J Periodontics Restorative Dent 13, 9-27.

8. Paolantonio M (2002) Combined periodontal regenerative technique in human intrabony defects by collagen membranes and anorganic bovine bone. A controlled clinical study. J Periodontol 73, 158-166.

9. Chen CC, Wang HL, Smith F, Glickman GN, Shyr Y, O'Neal RB (1995) Evaluation of a collagen membrane with and without bone grafts in treating periodontal intrabony defects. J Periodontol 66, 838-847.

10. Gouldin AG, Fayad S, Mellonig JT (1996) Evaluation of guided tissue regeneration in interproximal defects. II. Membrane and bone versus membrane alone. J Clin Periodontol 23, 485-491.

11. Kim CK, Choi EJ, Cho KS, Chai JK, Wikesjö UM (1996) Periodontal repair in intrabony defects treated with a calcium carbonate implant and guided tissue regeneration. J Periodontol 67, 13011306.

12. Kiliç AR, Efeoğlu E, Yilmaz S (1997) Guided tissue regeneration in conjunction with hydroxyapatitecollagen grafts for intrabony defects. A clinical and radiological evaluation. J Clin Periodontol 24, 372-383.

13. Batista EL Jr, Novaes AB Jr, Simonpietri JJ, Batista FC (1999) Use of bovine-derived anorganic bone associated with guided tissue regeneration in intrabony defects. Six-month evaluation at re-entry. J Periodontol 70, 1000-1007.

14. Trejo PM, Weltman R, Caffesse R (2000) Treatment of intraosseous defects with bioabsorbable barriers alone or in combination with decalcified freeze-dried bone allograft: a randomized clinical trial. J Periodontol 71, 1852-1861.

15. Mellado JR, Salkin LM, Freedman AL, Stein MD (1995) A comparative study of ePTFE periodontal membranes with and without decalcified freeze-dried bone allografts for the regeneration of interproximal intraosseous defects. J Periodontol 66, 751-755.

16. Stahl SS, Froum S (1991) Histologic healing responses in human vertical lesions following the use of osseous allografts and barrier membranes. J Clin Periodontol 18, 149-152.

17. Precheur HV (2007) Bone graft materials. Dent Clin North Am 51, 729-746.

18. Hench LL, West JK (1996) Biological application of bioactive glasses. Life Chem Rep 13, 187-241.

19. Wilson J, Low SB (1992) Bioactive ceramics for periodontal treatment: comparative studies in the Patus monkey. J Appl Biomater 3, 123-129.

20. Fetner AE, Hartigan MS, Low SB (1994) Periodontal repair using PerioGlas in non-human primates: clinical and histologic observations. Compendium 15, 932-938.

21. Karatzas S, Zavras A, Greenspan D, Amar S (1999) Histologic observations of periodontal wound healing after treatment with PerioGlas in nonhuman primates. Int J Periodontics Restorative Dent 19, 489-499.

22. Shapoff CA, Alexander DC, Clark AE (1997) Clinical use of a bioactive glass particulate in the treatment of human osseous defects. Compend Contin Educ Dent 18, 352-363.

23. Low SB, King CJ, Krieger J (1997) An evaluation of bioactive ceramic in the treatment of periodontal osseous defects. Int $\mathrm{J}$ Periodontics Restorative 
Dent 17, 358-367.

24. Nevins ML, Camelo M, Nevins M, King CJ, Oringer RJ, Schenk RK, Fiorellini JP (2000) Human histologic evaluation of bioactive ceramic in the treatment of periodontal osseous defects. Int J Periodontics Restorative Dent 20, 458-467.

25. Silness J, Loe H (1964) Periodontal disease in pregnancy. II. Correlation between oral hygiene and periodontal condition. Acta Odontol Scand 22, 121-135.

26. Loe H, Silness J (1963) Periodontal disease in pregnancy. I. Prevalence and severity. Acta Odontol Scand 21, 533-551.

27. Machtei EE (2001) The effect of membrane exposure on the outcome of regenerative procedures in humans: a meta-analysis. J Periodontol 72, 512-516.

28. Parrish LC, Miyamoto T, Fong N, Mattson JS, Cerutis DR (2009) Non-bioabsorbable vs. bioabsorbable membrane: assessment of their clinical efficacy in guided tissue regeneration technique. A systematic review. J Oral Sci 51, 383-400.

29. Wikesjö UME, Selvig KA (1999) Periodontal wound healing and regeneration. Periodontol 2000 19, 21-39.

30. Zafiropoulos GG, Hoffmann O, Kasaj A,
Willershausen B, Weiss O, Van Dyke TE (2007) Treatment of intrabony defects using guided tissue regeneration and autogenous spongiosa alone or combined with hydroxyapatite/ $\beta$-tricalcium phosphate bone substitute or bovine-derived xenograft. J Periodontol 78, 2216-2225.

31. Lohmann CH, Andreacchio D, Köster G, Carnes DL Jr, Cochran DL, Dean DD, Boyan BD, Schwartz Z (2001) Tissue response and osteoinduction of human bone grafts in vivo. Arch Orthop Trauma Surg 121, 583-590.

32. Zahran FM (2000) Combined bioglass and autogenous bone graft in the treatment of periodontal osseous defects. Egypt Dent J 46, 2287-2298.

33. Cordioli G, Mazzocco C, Schepers E, Brugnolo E, Majzoub Z (2001) Maxillary sinus floor augmentation using bioactive glass granules and autogenous bone with simultaneous implant placement. Clinical and histological findings. Clin Oral Implants Res 12, 270-278.

34. Galindo-Moreno P, Avila G, Fernández-Barbero JE, Mesa F, O'Valle-Ravassa F, Wang HL (2008) Clinical and histologic comparison of two different composite grafts for sinus augmentation: a pilot clinical trial. Clin Oral Implants Res 19, 755-759. 